\title{
EL HORMIGON PRETENSADO EN LA ARQUITECTURA
}

\author{
(PRE-STRESSED CONCRETE IN ARCHITECTURE)
}

Alfredo Páez Balaca, Dr. Ingeniero de Caminos.

Fecha de recepción: $11 \times \times \cdot 88$

\begin{abstract}
RESUMEN
En este artículo, el autor defiende el principio de que es en el diseño donde, principalmente, reside el acierto y la originalidad del proyecto. Puesto que en esta primera fase es donde se tantean las diversas opciones imaginadas, convendrá considerar el pretensado como una técnica que, dotada de unas especiales características, implica la aplicación de unos procedimientos que pueden modificar el comportamiento de la estructura llegando a determinar soluciones notablemente simples.
\end{abstract}

A estos efectos, y con la finalidad de exponer intuitivamente estos conceptos, se desarrollan unos ejemplos ilustrativos de las posibilidades que ofrece el hormigón pretensado en el caso particular de las cubiertas de edificios singulares.

\section{SUMMARY}

In this article, the writer upholds the principle that the success and originality of the project lie principally in the design. Since this first stage is where all the different possibilities imagined are sounded out, it would be worth considering pre-stressing as a technique which, possessing specific characteristics, would imply the application of some processes which could modify the structural behaviour leading to identify remarkably simple solutions.

To this end, and with the object of intuitively putting forth these ideas, some examples have been set out which illustrate the possibilities of offering pre-stressed concrete in the specific case of roofs of detached buildings.

\section{LAS CUBIERTAS}

Con la salvedad de contadas excepciones, el hormigón pretensado ofrece unas ventajas que primordialmente se manifiestan en las estructuras llamadas singulares, bien sea por la importancia del vano que salvan, bien por las especiales circunstancias que rodean su ejecución, o bien por sus particulares requisitos de impermeabilidad o resistencia frente a fenómenos de fatiga. Puesto que ninguna de estas condiciones concurren ordinariamente en la construcción de viviendas, lógico es que, en este dominio estructural, la técnica del pretensado se limite al empleo de sus viguetas, unas piezas que por venir prefabricadas, ofrecen la incuestionable ventaja de una mayor economia respecto a los equivalentes perfiles metálicos, una mayor durabilidad, y un mejor comportamiento frente a los efectos de un posible incendio declarado en el interior del edificio. Así resulta que, cuantitativamente, la mayor parte de la producción de aceros de muy alta resistencia mecánica se destine a este mercado sin que por ello pueda afirmarse que la edificación sea el principal campo de aplicación del pretensado. En realidad, un edificio convencionalmente construido con estos elementos prefabricados, no se considera como una solución pretensada a menos que la estuctura, es decir el entramado resistente que soporta esos elementos, lo sea efectivamente.

Lo extraño, lo que verdaderamente sorprende, es el corto número de edificios singulares pretensados que se han construido. No sólo las naves industriales suelen exigir amplios vanos por la versatilidad de las operaciones que en su interior se desarollan; también se requiere la creación de grandes espacios diáfanos en multitud de edificios públicos. Las estaciones de autobuses; las salas de recepción de pasajeros en las terminales maritimas y aéreas; los edificios feriales; los grandes auditorios para festivales, congresos y paraninfos; las piscinas cubiertas y los graderios de las instalaciones deportivas; las basílicas; los teatros y los cines de gran aforo; son recintos cuya función de albergar un público numeroso, implica la necesidad de cubrir amplias áreas preferiblemente diáfanas. 


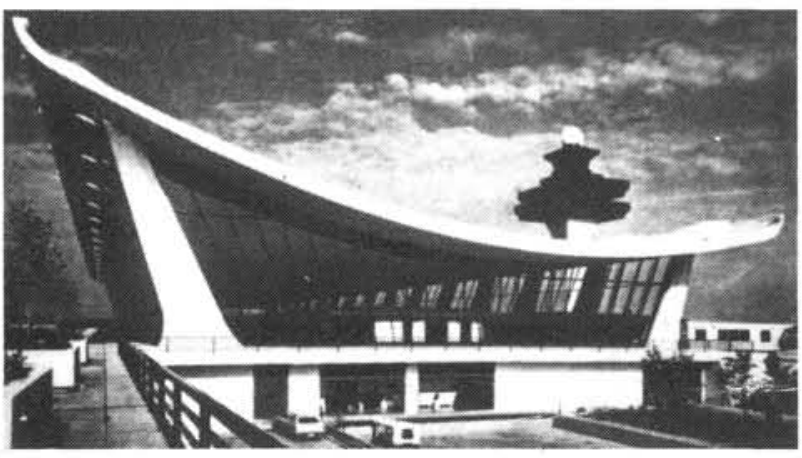

Fig. 1.-Aeropuerto de Washington (arquitecto E. Saarinen).

A poco importante que sea la luz de ese vano, la cubierta destacará como un elemento con la suficiente entidad como para influir decisivamente en la compo. sición del conjunto estructural. Según la forma de la cubierta y la distribución de sus apoyos, el edificio deberá reflejar ese equilibrio estático en la armónica disposición de las fachadas (figura 1). Si esa transmisión de las cargas se esconde tras unos paños inexpresivos, puede producirnos la perplejidad que sentimos an. te la enigmática sonrisa de La Gioconda de Leonardo. Tan impasible como la Esfinge, sus ragos no nos comunican otra sensación que el fallido intento del artista en representar el carácter de un personaje mediante un rostro apático y desangelado.

Puesto que cada material tiene sus peculiares características mecánicas, distinta será la forma de una cubierta según sea de hormigón pretensado, de hormigón armado, metálica, o mixta. El principal problema del diseño consiste en tantear diversas soluciones a fin de seleccionar aquella que parece reunir mayores ventajas y menores inconvenientes. Aunque intuitivo en sus comienzos, esta búsqueda de la óptima solución para un caso concreto, implica la imaginativa labor de perfilar ese conjunto de posibles disposiciones resistentes, cuanto más distintas mejor, a fin de que la citada selección pueda alcanzar los apropiados niveles de economia y funcionalidad.

Un quimérico equipo de proyectistas, dotados de una inventiva sin limites, conocedores de todas las particularidades de la materia así como de la sucesión de los acontecimientos que afectarán a la estructura durante su futuro período de servicio, y en disposición de unos medios infalibles para determinar los pésimos estados de tensión de las piezas que componen el entramado resistente, podría ser capaz de concebir todas las soluciones plausibles o factibles. En semejante proceso ideal, podría seleccionarse, entre la infinidad de soluciones, aquella que, ajustándose de un modo armonioso y perfecto al entorno, exigiese un mínimo esfuerzo para su ejecución. Esa utópica solución seria necesariamente única. Si pudiera realizarse, quedariamos admirados al contemplar la belleza que irradia la absoluta perfección de sus formas.
En nuestra limitación humana, nos vemos obligados a resolver problemas deficientemente definidos. Incapaces de imaginar las infinitas soluciones posibles, nos contentamos con unos pocos modelos, a veces basados en las pautas legadas por los que nos precedieron. Sólo con un obstinado deseo de superación, podremos acercarnos a aquel quimérico ideal que presentimos.

Cuando resignadamente aceptamos como buena la mejor de las pocas soluciones ensayadas, procedemos a su definición geométrica como base necesaria para iniciar un cálculo cuyos datos son el verdadero problema. Desconocedores del futuro, confiamos a una estadistica, no muy apropiada, la presunción de unas cargas cuya magnitud y secuencia ignoramos. Esa anticipación a lo que conjeturamos puede suceder con una cierta probabilidad, conforma y define lo que entendemos por comprobación teórica de la estructura. Los mismos factores económicos están sujetos a numerosos imponderables: el montaje de una frágil cimbra sobre el cauce de un torrente, puede ser la solución más barata para construir un puente, pero una inoportuna riada podrá arrastrar cimbra, puntales y encofrados, convirtiendo en fracaso lo que parecia ser una acertada solución de mínimo coste.

La utilización de un material nuevo cuya durabilidad desconocemos, la elección de un procedimiento convincente aunque poco experimentado todavía, la audacia de unas formas o sistemas estucturales de original creación, son riesgos que aceptamos o rechazamos según la fe en la firmeza de nuestros conocimientos y en la valoración subjetiva de los imponderables.

Si en esta fase previa de la elaboración del diseño estructural, mantenemos el criterio de que una solución pretensada es equivalente a otra de hormigón armado en la que las barras las hemos sustituido por unos tendones de igual capacidad mecánica, podremos afirmar que, sin estar del todo equivocados, estamos cometiendo el grave error conceptual de confundir la causa con

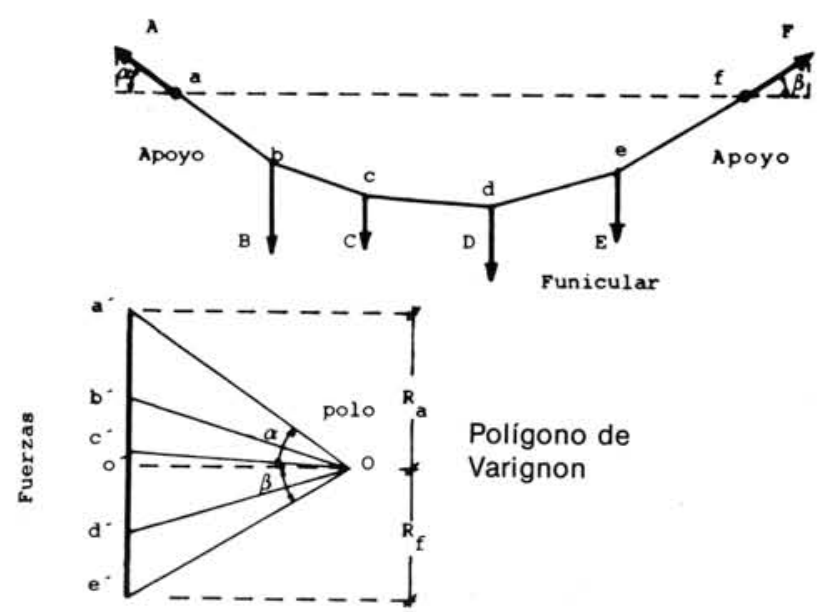

Fig. 2.-Estática de un hilo flexible.

http://informesdelaconstruccion.revistas.csic.es 
su efecto, un error que nos impide considerar el am. plio campo de interesantes soluciones que tal trans. formación ofrece.

Consideremos, primeramente, el clásico ejemplo de un hilo flexible sometido a la acción de unas cargas que, para simplificar, supondremos todas ellas verticales (figura 2). El llamado "poligono de Varignon", determina el trazado de ese hilo bajo la acción de tales cargas. Evidentemente, todo está en equilibrio. Las diferentes cargas aplicadas, por ser verticales, están equilibradas por la componente vertical de los extremos en donde el alambre se amarra. En estos terminales, la componente horizontal de apoyo es la misma en uno y otro lado. Siendo asi, un simple codal (figura 3), absorbe esa componente, transmitiéndose a los apoyos las reacciones verticales $R_{a}$ y $R_{i}$. Si ahora ampliamos las dimensiones del codal de tal modo que pueda contener en su interior el trazado del cable (figura 4), el conjunto parecerá exteriormente una viga, aunque en realidad se trate de una pieza (el codal) sometida a compresión simple. Ha bastado con anclar el cable en sus extremos a y $f$ y someterle a la tracción definida en el polígono de Varignon para que, en sus codos, aparezcan unas cargas iguales y contrarias a las aplicadas, con lo cual todas se anulan y sólo queda la carga horizontal $H$ que comprime el codal.

Si las cargas aplicadas, en vez de estar aisladas o concentradas en determinados puntos, se repartieran uniformemente, el trazado del funicular sería una parábola de segundo grado. Con semejante disposición, el cable ejerce, hacia arriba, una carga uniformemente repartida. Una adecuada tensión en el cable parabólico puede compensar así el peso propio del hormigón del codal. En esas condiciones el hormigón de la pieza formada por ese codal, está sometido a una misma compresión en todos sus puntos. Su flecha, por consiguiente, es nula. Todo aparece como si el hormigón hubiese perdido su peso ya que en ninguna sección actúa esfuerzo cortante alguno. Las reacciones de apoyo se reducen a ser la componente vertical de la tracción ejercida por el cable, una componente que, como puede fácilmente comprobarse, es igual a la mitad del peso real de la viga.

Sea, a título de ejemplo, el caso de una cubierta formada por una serie de segmentos cilíndricos (figura 5) apoyados en dos fachadas opuestas. Con esta disposición tan sencilla, la cobertura de la nave consiste en un conjunto de vigas paralelas, cuya sección abovedada se representa en la figura 6 , simplemente apoyadas en los muros extremos. Si $G$ es el baricentro geométrico de esa sección de canto total $h$, la viga-bóveda quedará representada en alzado en la forma indicada en la figura 7. La recta $I D$, lugar geométrico de los puntos $G$, define la directriz rectilínea de la pieza. El funicular $I C D$ representa la forma que tomaría un cable bajo

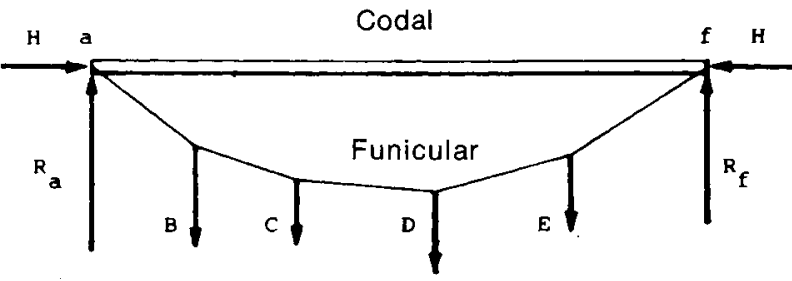

Fig. 3.- Hilo sustentador de unas cargas, suspendido de un codal

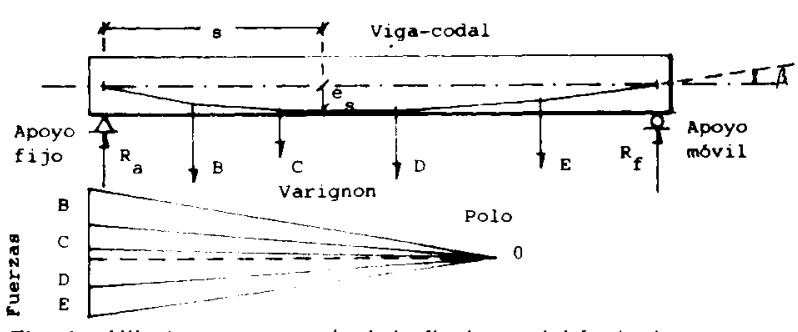

Fig. 4.-Hilo tenso para reducir la flecha e, del funicular.

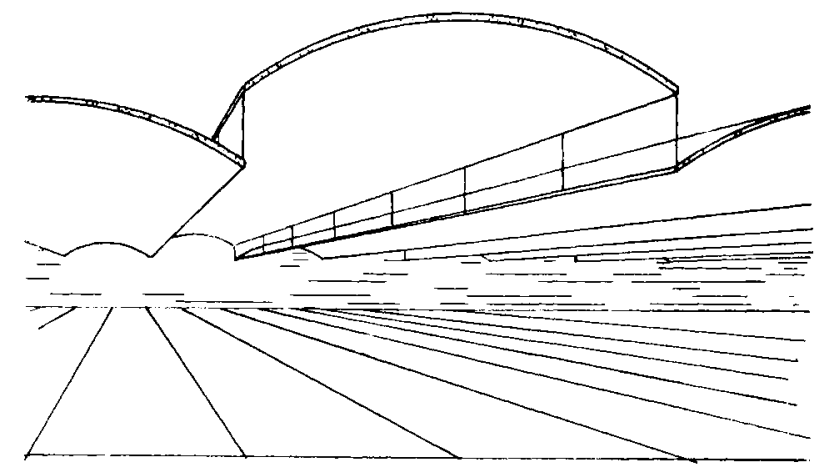

Fig. 5.-Cubierta cilindrica, simplemente apoyada en dos muros extremos.

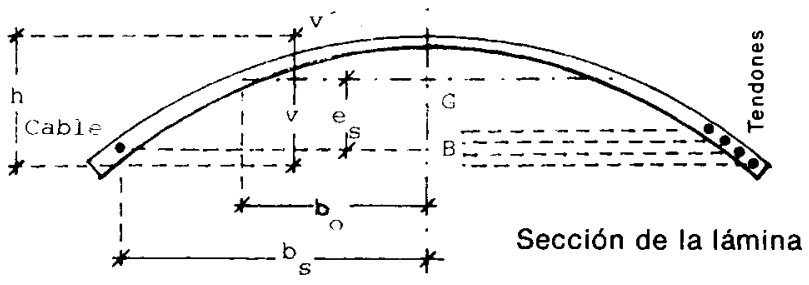

Fig. 6.-Descomposición del teórico hilo funicular, en parejas de tendones embutidos en el espesor de la lámina.

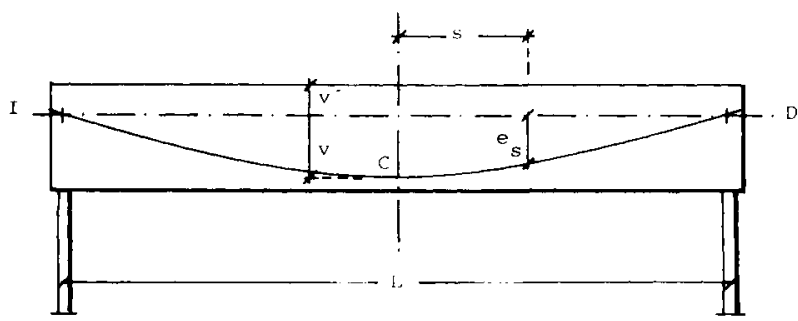

Fig. 7.-Cable baricéntrico de las armaduras activas. 
Informes de la Construcción, Vol. 40 n. ${ }^{\circ} 398$, noviembre/diciembre, 1988

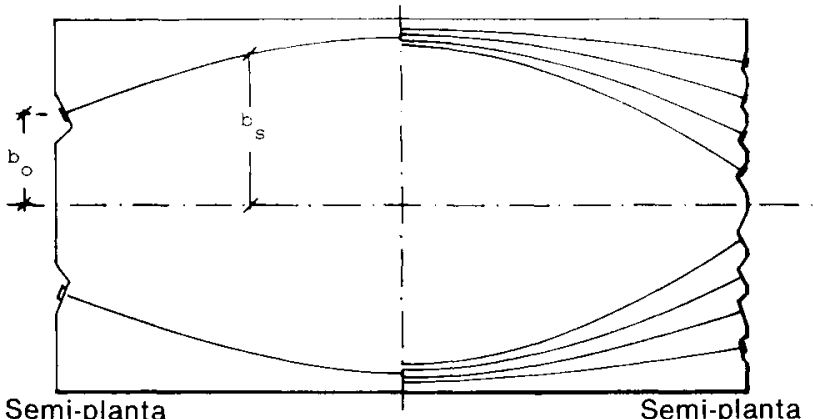

Fig. 8.-Descomposición del cable teórico en tendones cobaricéntri. cos.

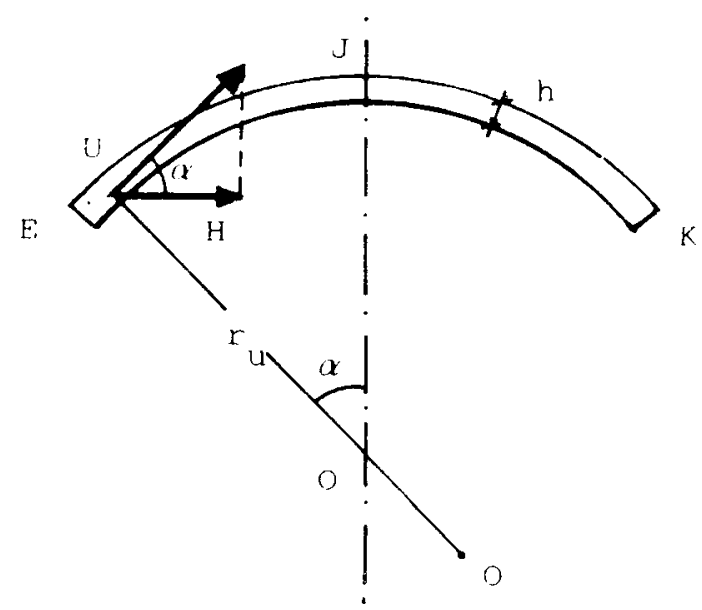

Fig. 9.-Sección transversal de una lámina cilindrica de espesor variable.

la acción de la carga uniformemente repartida del peso propio de la viga-bóveda. Bastará con disponer ese cable, tensado a la correspondiente carga $N_{p}$, con una excentricidad $e_{s}$ en cada punto parabólicamente variable, para que el codal de hormigón $1 D$ que solidariza los extremos del cable hipotético $I C D$ quede sometido a la compresión centrada $N_{p}$.

Cierto es que no resulta factible mantener en el aire el cable parabólico $I C D$ definido como lugar geométrico de los puntos $B$ (figura 6 ) que distan $e_{s}$ del punto $G$. Sin embargo nada se opone a la solución de descomponer el cable $B$ en dos, uno el $B^{\prime}$ y otro el $B^{\prime \prime}$, ambos situados dentro de la sección de hormigón supuesta simétrica respecto al plano vertical GB. A cada excentricidad $e_{s}$, le corresponde así, a cada lado o faldón de la bóveda, una distancia $b_{s}$ del tendón al plano vertical de simetría. Tampoco nada se opone a la consideración de subdividir estos semicables B' y $B$ " en cuatro parejas de tendones como se indica en la semisección derecha de la figura 6 . En la figura 8 se representa la distribución en planta de las dos soluciones de semicables: la de dos tendones a la izquierda, y la de cuatro parejas de tendones en la semiplanta derecha.

(c) Consejo Superior de Investigaciones Científicas Licencia Creative Commons 3.0 España (by-nc)
La curvatura de estos tendones hace que, en una longitud elemental $d s$ de pieza, aparezcan unas fuerzas transversales dirigidas hacia la cumbrera de la bóveda (figura 9), fuerzas cuya componente vertical equilibra el peso, también elemental, de esa rebanada de espesor $d s$. Por evidentes condiciones de equilibrio, la componente horizontal de esas fuerzas se mantiene constante. Transversalmente la pieza es una auténtica bóveda cuyo peso se equilibra con la curvatura de los tendones activos.

Mediante esta disposición de tendones, obtenemos una cubierta laminar que goza de la inapreciable cualidad de que, bajo la acción de su peso propio, el hormigón trabaja en un estado de bicompresión en el que las tensiones principales son las mismas en todos los puntos. Tanto la cumbrera como los faldones, son generatrices rectas que no presentan flecha alguna.

Es evidente que bajo la acción de las sobrecargas accidentales (viento y nieve), esta lámina sufrirá unos adicionales estados de tensión que se superpondrán al precedente estado de bicompresión constante; pero cuando estas sobrecargas cesen, la cubierta volverá a recuperar su flecha nula y su habitual régimen de com. presiones unitarias uniformemente repartidas.

Como puede observarse, el criterio sustentador de este modo de proceder consiste en crear artificialmente, mediante la acción activa de unos tendones pretensados, unas fuerzas que, por poderse considerar como exteriores al sistema estructural, equilibren las cargas debidas a la acción permanente del peso propio de la cubierta o estructura en general. Las ventajas que se derivan de este criterio de diseño, universalmente conocido bajo la denominación de los "pretensados ideales", son múltiples. Sometido el hormigón a un régimen uniforme de compresiones, se elimina todo riesgo de fisuración; las armaduras quedan perfectamente defendidas en el interior de esa masa alcalina que las envuelve, a la vez que la impermeabilidad conseguida repercute muy favorablemente en la durabilidad de una cubierta que satisface plenamente su función primaria de albergar y ofreciendo una resistencia frente a los efectos de un incendio muy superior a la de las estructuras metálicas. Al quedar equilibradas las cargas, la flecha es nula; sólo las sobrecargas que posteriormente actúen, modificarán ese ideal estado tensional.

Esta particularidad de las piezas pretensadas hace que su cálculo se simplifique al límite, circunstancia que permite no sólo un planteamiento directo de la estática del conjunto con su nítida expresión funcional, sino también una más sencilla deducción de las soluciones y formas que se consideran como óptimas. En el hormigón armado, una lámina como la propuesta en el ejemplo anterior, implica el desarrollo de un cálculo hiperestático extraordinariamente laborioso y basado en numerosas hipótesis simplistas. En el hormigón prehttp://informesdelaconstruccion.revistas.csic.es 
tensado unas meras consideraciones estáticas han bastado para deducir el trazado ideal de los tendones de la armadura activa.

Pero esta solución de transformar en simple codal lo que en realidad es una viga, es sólo un ejemplo de las posibilidades que ofrece la técnica del pretensado. Según que la disposición general de la cubierta sea una u otra, podremos crear estados artificiales de tensión destinados a configurar sistemas exteriores de cargas que se consideren como beneficiosas para neutralizar pesos u otras acciones permanentes. A estos efectos, y para ampliar los anteriores conceptos, dividiremos las cubiertas en los siguientes grupos estructurales de análoga tipologia:

a) Láminas cilindricas colgadas; b) Cubiertas de revolución; c) Soluciones mixtas.

\section{LAMINAS CILINDRICAS COLGADAS}

Esta forma estructural tiene una adecuada adaptación a la técnica del pretensado. Si para cubrir el espacio comprendido entre dos fachadas o líneas paralelas de sustentación, se disponen unos tendones que transversalmente salvan el vano formando una catenaria ( $\mathrm{fi}$ gura 10), bastará con colgar de esos cables un encofrado para que pueda hormigonarse la superficie sin ayuda de cimbra alguna. A medida que el hormigona-

a

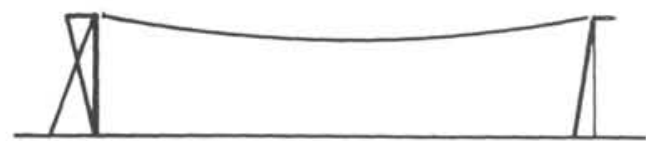

b

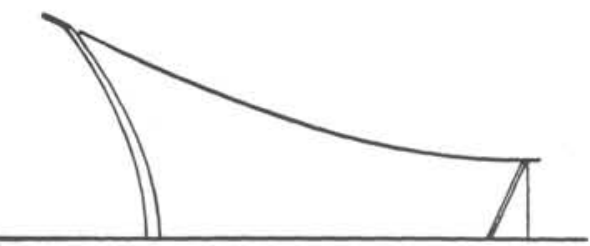

c

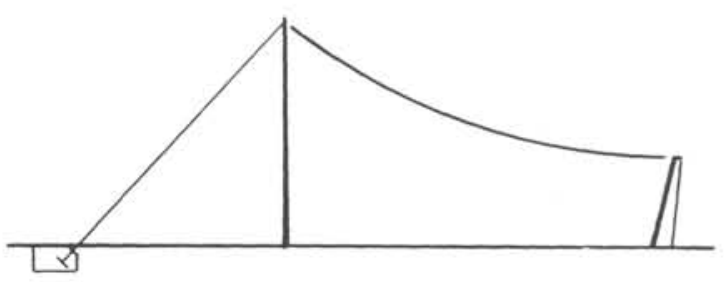

d

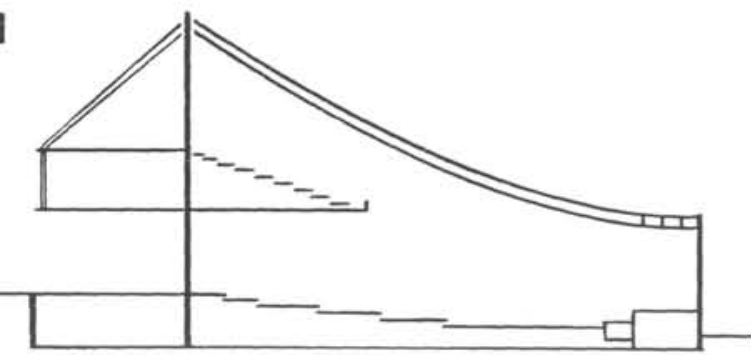

Fig. 10.-Diferentes soluciones de láminas colgadas. do progresa, la tensión en los alambres irá aumentando, así como la correspondiente reacción en las retenciones o anclajes sobre ambas líneas de apoyo. Cuando el hormigón vertido endurece, no queda sometido a tensión alguna, bastando con acortar ligeramente la flecha de la catenaria para que el acortamiento inducido compense el efecto de la retracción. Mientras queden abiertas las juntas extremas de la lámina, puede ajustarse la flecha de la catenaria corrigiendo la tensión de los distintos tendones sustentadores hasta conseguir que la directriz o sección transversal sea rectilinea y horizontal (figura 10 a). Obsérvese que el conjunto de alambres que compone cada tendón está alojado dentro de una vaina, no existiendo, hasta que se proceda a la inyección final, adherencia alguna de la armadura activa con el hormigón envolvente. Bloqueadas las juntas, todo incremento de tensión en los tendones, se traduce en un acortamiento de la flecha y, por consiguiente, en una compresión o acortamiento longitudinal del hormigón envolvente. Las figuras $11 \mathrm{y}$ 12 muestran la importancia que alcanzan los contrafuertes de retención de la lámina.

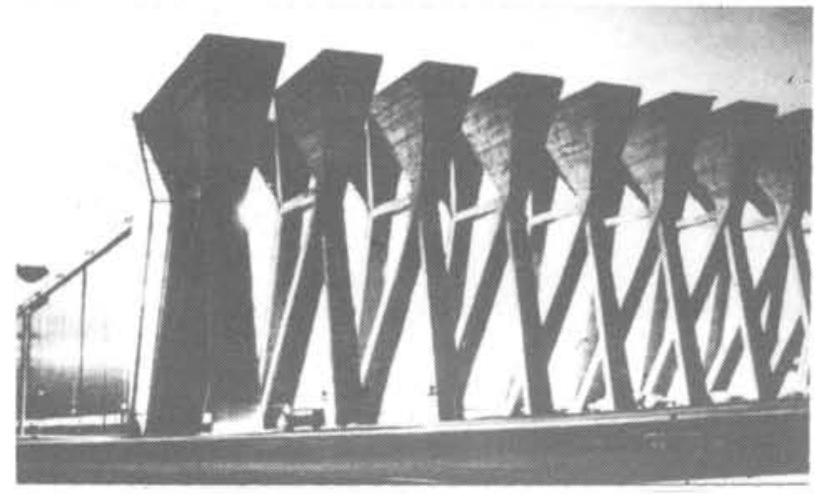

Fig. 11.-Hangar de dos vanos de $130 \mathrm{~m}$ de luz en el aeropuerto de Frankfurt. La lámina, de hormigón ligero, está pretensada con barras Dywidag.

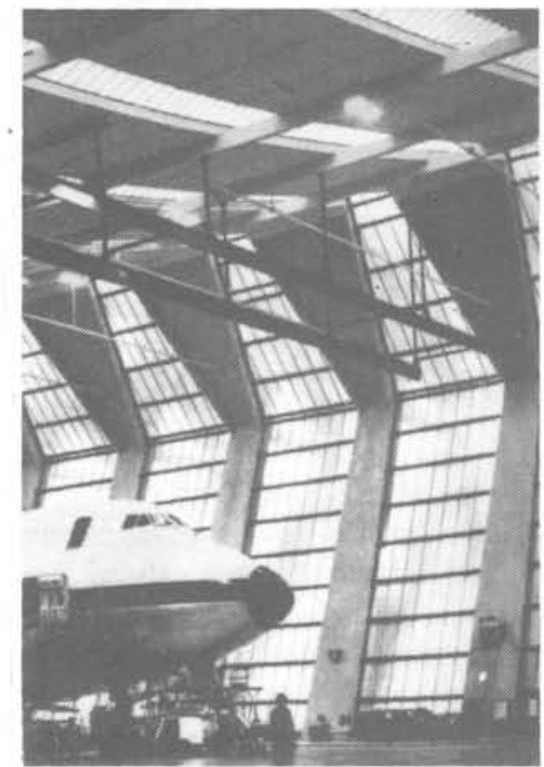

Fig. 12.-Vista del interior del hangar de Frankfurt (altura interior minima $25 \mathrm{~m}$ ). 


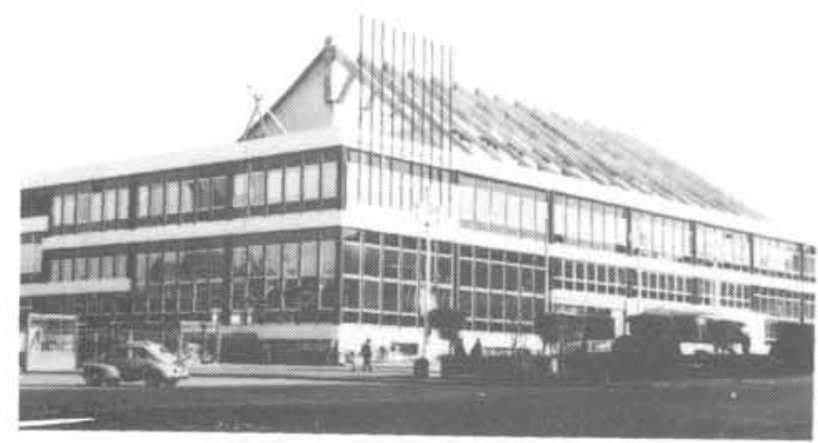

Fig. 13. - Fachada sur del Palacio de Congresos de Barcelona. Los tirantes inclinados compensan la componente horizontal de la tracción ejercida por la cubierta del salón de actos.

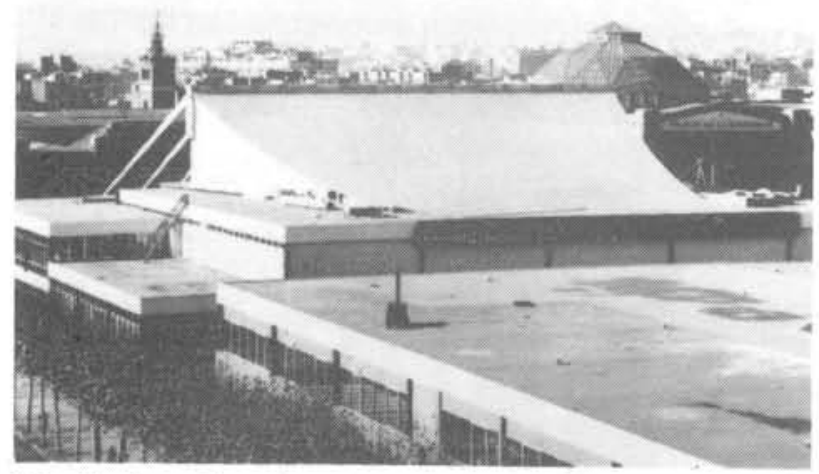

Fig. 14.-La cubierta vista desde el norte.

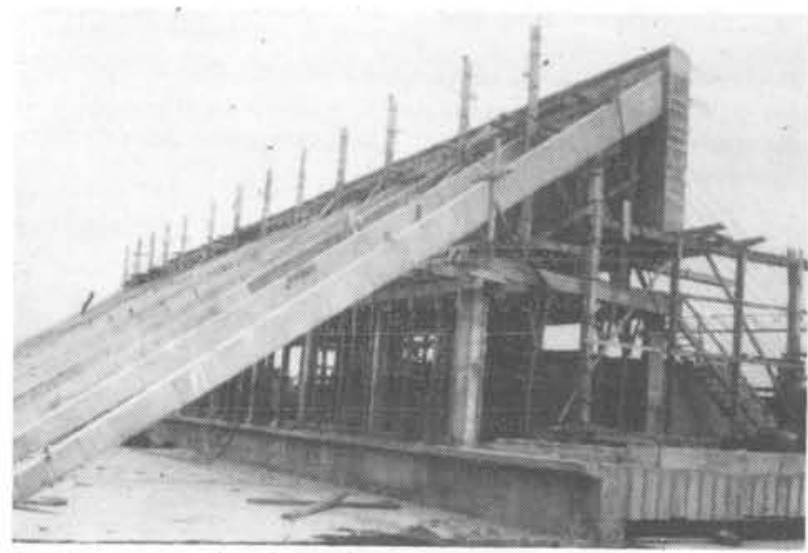

Fig. 15.-Colocación de los tirantes de compensación como elemen tos de arriostramiento lateral de la viga cumbrera.

La solución (b) de la figura 10 no es más que una variante de la (a) en la cual las dos líneas paralelas de apo. yo no están situadas a la misma altura. En ambos casos la lámina así colgada ejerce una fuerte tracción so. bre el borde de apoyo, esfuerzo tanto mayor cuanto menor sea la flecha dada a la catenaria. La solución (c) consiste en equilibrar la componente horizontal de esta tracción mediante tirantes anclados al suelo. La solu. ción (d) representa la sección longitudinal de un audi- torio en donde los tirantes inclinados de compensación (figura 13), equilibran la acción ejercida por la lámina sobre la cumbrera (figura 14) al par que suspenden, con su reacción vertical, la entreplanta situada a la altura del acceso al anfiteatro. La componente horizontal de los tirantes se transmite, por la losa de anclaje, a los muros laterales del recinto, muros que a su vez retienen, al mismo nivel, la viga-cajón que constituye el techo del escenario y cuyas reacciones horizontales extremas se neutralizan con la ejercida por los tirantes de fachada.

La doble linea que en la figura $10 \mathrm{~d}$ representa la cubierta del recinto, expresa la existencia de dos láminas superpuestas a fin de crear una cámara que mejore el aislamiento térmico y aloje con sobrada amplitud los conductos de aire acondicionado. Al contrario, la doble línea de los tirantes situados sobre el vestíbulo, determinan un espesor no seccionado por el corte idealmente dado al edificio.

La construcción de la cubierta se inicia colocando los tirantes prefabricados de tal modo que arriostren la viga cumbrera del edificio (figura 15). Al otro lado, los tendones que constituyen la armadura activa principal, enfundados en sus correspondientes vainas, forman una catenaria que desciende hasta el techo del escenario (figura 16). Distribuyendo la armadura activa en un suficiente número de tendones para que su separación sea inferior al medio metro, los carpinteros pueden ins. talar tablones que les permita trabajar, sin riesgo, en la elevación y atornillado de unos tableros (figura 17) que constituyen el encofrado de una lámina que, por razones de mínimo peso propio, sólo tiene 4 centímetros de espesor. Estimándose que la madera constitu. ye el material más apropiado para lograr las mejores condiciones acústicas, los tableros eran de nogal, previamente barnizados en su cara inferior, de tal modo que su calidad, textura y acabado, permitieran dejarlos como definitivo revestimiento del techo de la sala, replanteándose en ellos las acometidas de los conductos de aire acondicionado y de las instalaciones eléc.

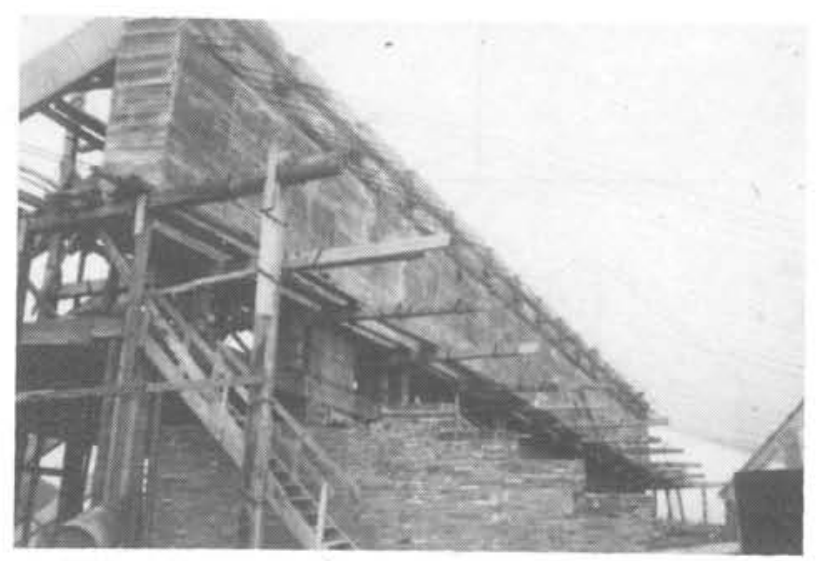

Fig. 16.-Anfiteatro y anclaje de los tendones principales en la viga cumbrera. 
tricas. Para que la humedad del hormigón sobre ellos vertido, no deteriorara una madera de tanta calidad, los tableros se izaron superiormente protegidos por una membrana de plástico (figura 18), sólo perforada por los tornillos y hembrillas que siven de sujeción a las abrazaderas que cuelgan de los tendones, y a la masa de hormigón cuya adherencia con el tablero queda interrumpida por la hoja de plástico. Obviamente la lámina superior (figura 19), del mismo espesor que la primera, se hormigonó sobre unos tableros de madera or. dinaria.

Transversalmente a la armadura principal, una armadura activa secundaria, alojada en tendones horizontales y rectilineos, tiene la misión complementaria de introdu. cir una compresión transversal a fin de que la delgada lámina de hormigón resulte sometida a una bicompresión estimada como necesaria para eliminar todo posible principio de microfisuración. A estos efectos, y para reducir el gradiente térmico debido a la incidencia de los rayos solares sobre la lámina superior, esta última se revistió con una capa de betún recubierta por una plancha reflejante de aluminio ondulado para evitar improbables deslumbramientos y acumular en sus entrantes el polvo atmosférico.

Asi como el pretensado transversal no ofrece ninguna particularidad por quedar los bordes laterales de la lámina libres o despegados del cerramiento, el pretensado longitudinal o principal se hace necesario realizarlo en dos fases. Colgado como está el encofrado, se interrumpe el hormigonado al llegar a la cumbrera para dejar una junta en toda su anchura. Una vez endurecido el hormigón, y dada la gran flexibilidad de la lámina, se corrige ligeramente la tensión de los tendones hasta conseguir unas generatrices horizontales rectas. Rectificadas estas generatrices transversales, verdaderas curvas de nivel, se bloquea la junta. Todo incremento posterior en la tensión dada por los gatos, implica una disminución de la flecha y, por consiguiente, un acortamiento de la catenaria cuya deformación determina una compresión longitudinal de la lámina.

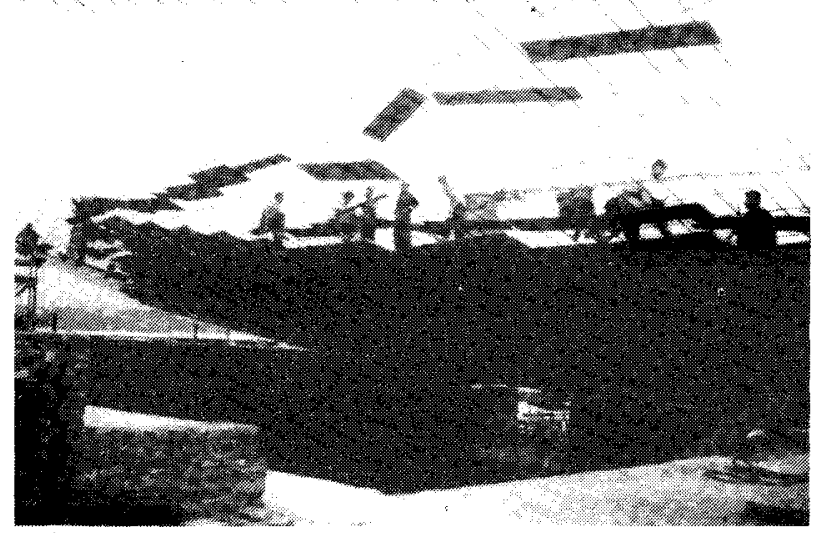

Fig. 17.-Colocación del encofrado suspendiéndolo de los tendones principales.

(c) Consejo Superior de Investigaciones Científicas Licencia Creative Commons 3.0 España (by-nc)

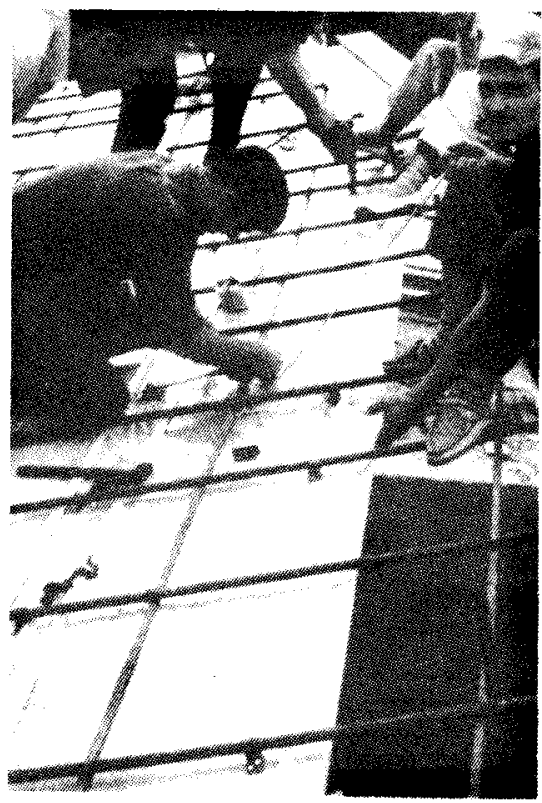

Fig. 18.-Atornillado de los tableros de nogal a los tendones principales.

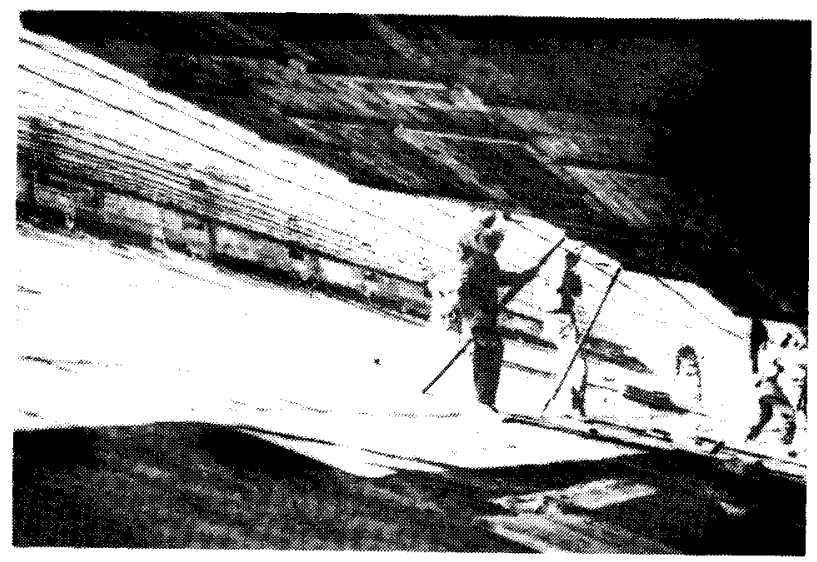

Fig. 19.-Montaje del encofrado ordinario para la segunda lámina.

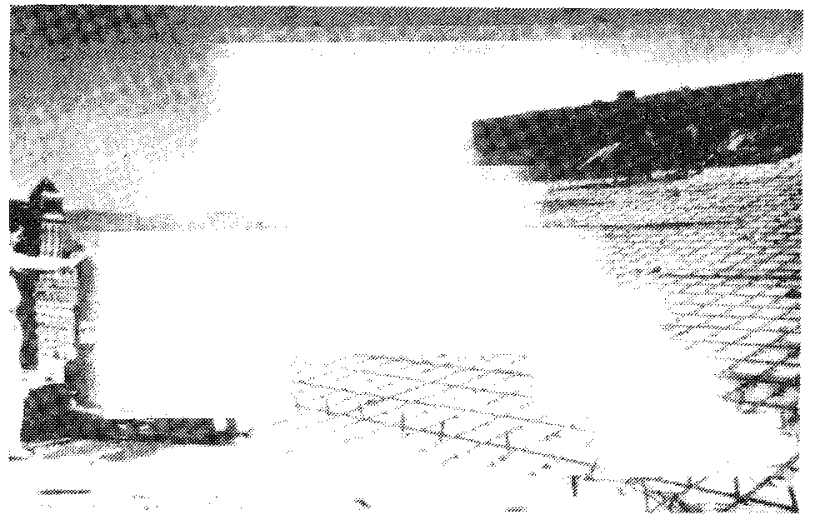

Fig. 20.-Lnyección de la papilla de cemento en la lámina inferior.

La figura 20 muestra la fase de inyección de la papilla de cemento en el interior de los tendones de la lámina inferior. La figura 21 es una vista interior de este auditorio para 1.500 espectadores en donde se aprecia la textura de los tableros de nogal y que son los paneles del encofrado que aparece en la figura 17. 


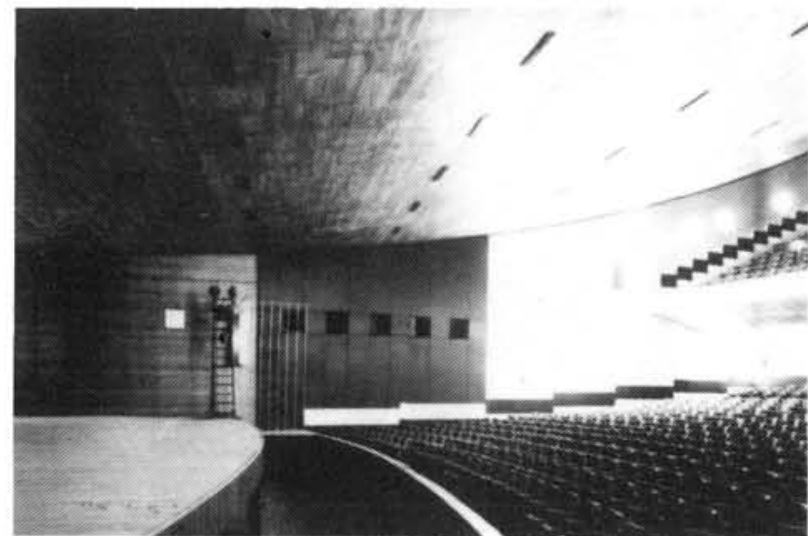

Fig. 21.-Interior del auditorio con su revestimiento de nogal empleado como encofrado de la lámina inferior de cubierta (figura 17).

Ciertamente que la utilización de un necesario revestimiento, como encofrado provisional, no pasa de ser una original anécdota de un proceso constructivo cuyo principio económico se establece en base a unos fundamentos netamente estructurales. La cobertura de ese salón de actos, con sus $40 \mathrm{~m}$ de anchura media y cerca de $50 \mathrm{~m}$ de fondo, se complica cuando tal espacio ocupa la zona central de un edificio que lo envuelve. Con semejantes vanos, cualquier entramado de vigas obliga a la colocación de elementos demasiado pesados para su sustentación por unas grúas situadas fuera del recinto. Si el cálculo de la lámina descrita es, por su naturaleza, extremadamente simple, tan sencillo o más es el proceso constructivo de unos encofrados planos formados por unos tableros que se cuelgan de una red de cables medianamente tupida para eliminar el riesgo de un posible accidente laboral; un sencillo procedimiento para unas láminas simplemente colgadas.

\section{CUBIERTAS DE REVOLUCION}

Una variante de las anteriores soluciones consiste en disponer radialmente los tendones principales colgándolos, en su punto más alto, de la corona circular delimitada por el borde superior del tambor que forma el cerramiento cilíndrico del recinto (figura 22). En el punto más bajo, los tendones se anclan en un anillo concéntrico que si bien resulta sometido a un fuerte esfuerzo de tracción, su desarrollo es corto. El anillo exterior, por el contrario, trabaja en compresión, circunstancia

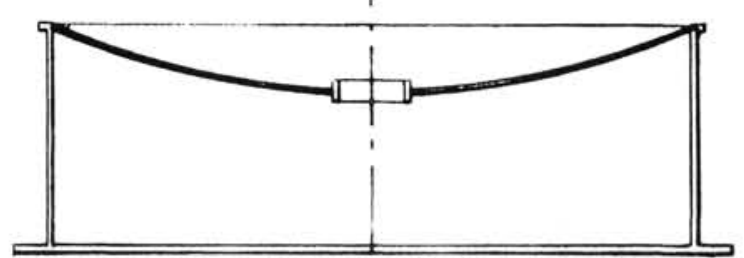

Fig. 22.-Solución de cubierta en cúpula invertida. Su mayor incon. veniente es la dificil evacuación del agua de lluvia. que permite un fácil apoyo sobre la coronación del muro de cerramiento.

Funcionalmente, esta solución axisimétrica tiene muchas ventajas. Tal vez la más importante sea su facilidad de construcción. Como en el caso anterior, el encofrado se suspende de los tendones ahora radiales. Su principal inconveniente es el de la evacuación del agua de lluvia que se almacena en torno al anillo central. En el antiguo Pabellón Deportivo de Montevideo, unos canalones de desagüe, interiores al recinto y colgados de la cubierta, canalizan el agua a un colector perimetral, pero la solución un tanto desaliñada por la presencia de esos tubos desproporcionadamente grandes, afean la estructura y perturban la visibilidad. Cierto es que basta con disponer una bomba aspirante que eleve el agua hasta la cornisa, pero semejante dispositivo mecánico tiene que contar con la garantía de un permanente automatismo que evite, de un modo radical, una acumulación de agua suficiente para desbordar los ineludibles aliviaderos limitadores de una sobrecarga máxima sobre la cubierta.

Si ahora, como antes se hiciera con la lámina colgada, se procediera a un desdoblamiento de la cubierta en dos capas, puede disponerse la superior con una inclinación suficiente para verter hacia el perímetro el agua de lluvia (figura 23). Con esta disposición en rueda de bicicleta caracteristica de la arquitectura de los años 60 , la cubierta se transforma en un disco con sus radios en tracción y su borde perimetral en compresión. El anillo central, ahora más alto, puede estar tapado por un cupulín. Las figuras 24 y 25 muestran el exterior y el interior de una solución de esa forma, construida con un hormigón ligero y en la que la luz natural penetra a través del muro perimetral de cerramiento transformado en un amplio y continuo ventanal.

Si contrariamente se construye una cúpula por encima del anillo exterior que define la cornisa, se invierten todos los términos: los sectores radiales trabajan en compresión, asi como el anillo central, mientras que el tambor de apoyo del casquete esférico se precisa pretensarlo para absorber las tracciones ejercidas por el empuje horizontal de los meridianos al llegar al anillo exterior de apoyo. La figura 26 muestra una disposición de esta forma. Esta solución estructural, repetida con diversas variantes para constituir pabellones de-

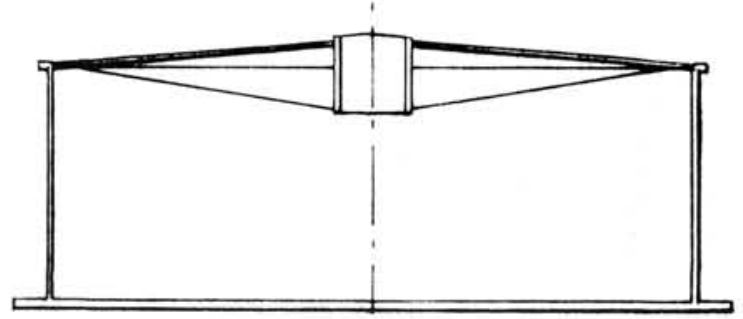

Fig. 23.-Desdoblamiento de tirantes para conseguir la conicidad ne. cesaria para la evacuación de la lluvia.

http://informesdelaconstruccion.revistas.csic.es 
portivos, alcanza sus máximas proporciones en la cúpula pretensada del estadio de Seattle (Estado de Was. hington) con sus 202 metros de diámetro y $33,50 \mathrm{~m}$ de flecha, con una capacidad de 65.000 espectadores.

Un curioso ejemplo de la aplicación del pretensado a la resolución de estructuras más complejas es el Edificio Ferial de la Exposición de Muestras de Barcelo. na, un pabellón destinado a la instalación de mostra. dores y puestos donde se exhiben los productos de las distintas casas comerciales. De planta rectangular, casi cuadrada, sus diferentes pisos se desarrollan como un helicoide alrededor del eje central a fin de acceder de un plano al siguiente mediante sucesivas rampas de comunicación, dejando un amplio patio central de acusada personalidad. Al llegar a la terraza, la interrumpe, dibujando un hueco octogonal con su intersección (figura 27).

La cubierta de este patio central, no sólo debe techarlo sino que, además, debe permitir la iluminación natural de las rampas que ascienden alrededor del hueco. El marcado eje vertical del edificio en ese entorno, hace pensar en una superficie de revolución, más que en una pirámide, a fin de presentar su punto más alto en el propio eje como solución apropiada para la evacuación de la lluvia a los laterales. Sin embargo, el casquete esférico, tan indicado como solución estructural, no permite la necesaria iluminación de ese ambiente central tan separado de las fachadas del pabellón. Para satisfacer esa condición y conjugar aspectos tan diferentes, se hace necesario disponer unos lunetos en su contorno seccionando el casquete esférico mediante planos inclinados (figura 28).

Al abrir esos lunetos, se altera profundamente el estado tensional de la cúpula, un estado que, de no presentar semejantes cortes, el material trabajaria en óptimas condiciones de bicompresión. En esta solución ideal, sin los lunetos, y en el supuesto de que el casquete se apoyara en todo el contorno, la reacción de apoyo debería orientarse según la tangente a los meridianos. Si contrariamente, el apoyo se dispusiera vertical, habria que recurrir a la tradicional solución de apoyar la cúpula sobre ese anillo horizontal que se pretensa para introducir una componente horizontal que, junto con la vertical de apoyo, corrija deformaciones y restablez$\mathrm{ca}$ las reacciones de equilibrio supuestas.

Pero cuando la cúpula está mutilada por los lunetos, el contorno lobulado que ahora aparece, perfila unos puntos aislados de apoyo en donde se concentran las reacciones de sustentación. El recorte efectuado, crea unos importantes esfuerzos de flexión y torsión, origen de fuertes tracciones. La cubierta deja de ser una membrana para pasar a ser una lámina cuyos espeso. res hay que aumentarlos, al menos en los bordes, asi

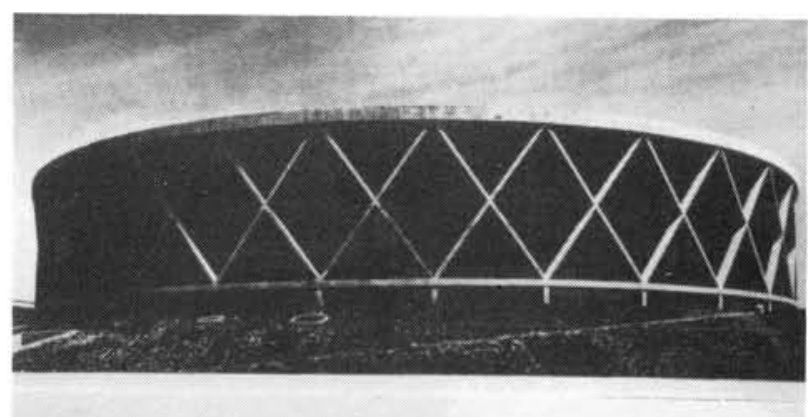

Fig. 24. - Pabellón polideportivo en Oakland (California) de $128 \mathrm{~m}$ de diámetro, construido con hormigón ligero y con capacidad para 15.000 espectadores.

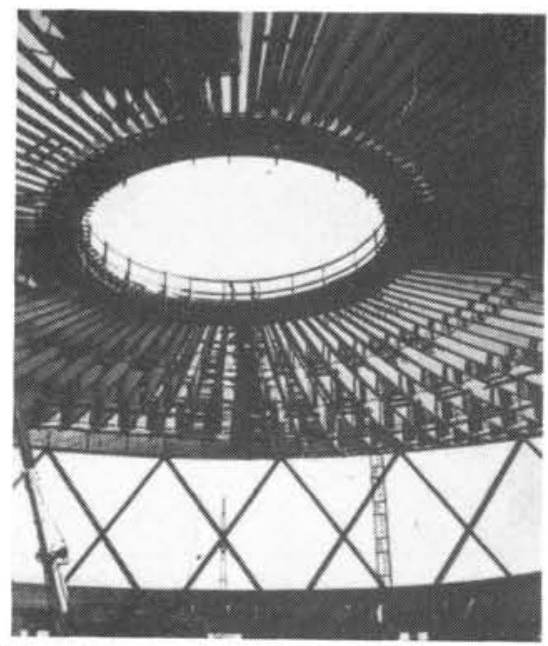

Fig. 25.-Vista del interior, durante su construcción a base de elemen tos radiales prefabricados.

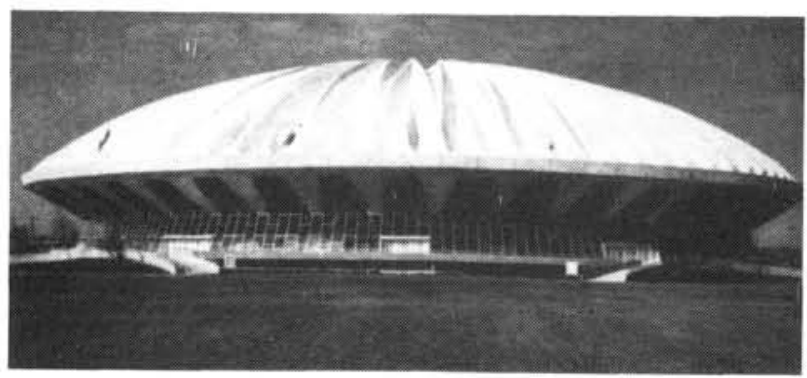

Fig. 26.-Auditorio de la Universidad de Illinois (Urbana), de 122 m de diámetro.

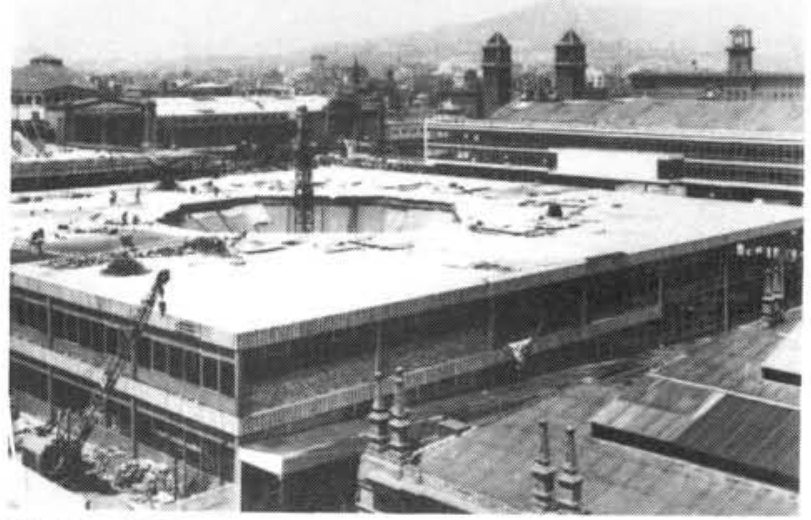

Fig. 27.-El Pabellón Ferial de Barcelona durante su construcción. En el centro de la terraza, el octógono que circunscribe el desa. rrollo de las rampas de acceso a las distintas plantas. 


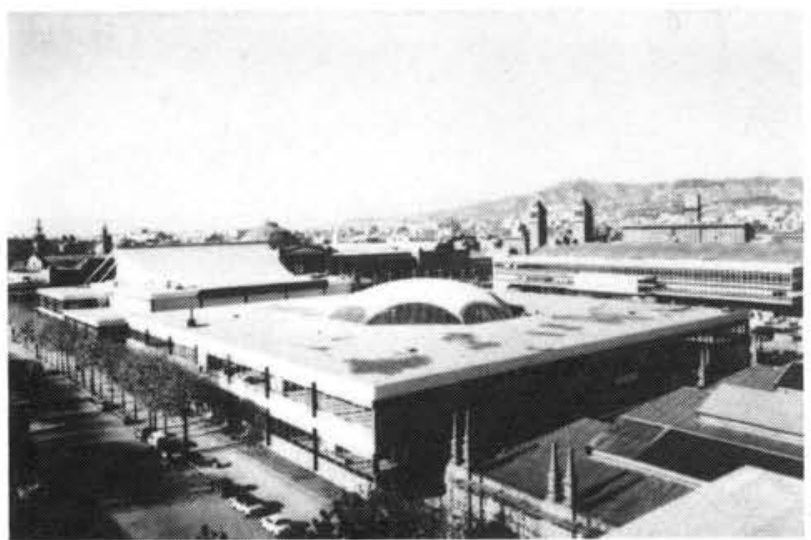

Fig. 28.-Los ocho lunetos de la cúpula, permiten la entrada de la luz natural al patio central del edificio.

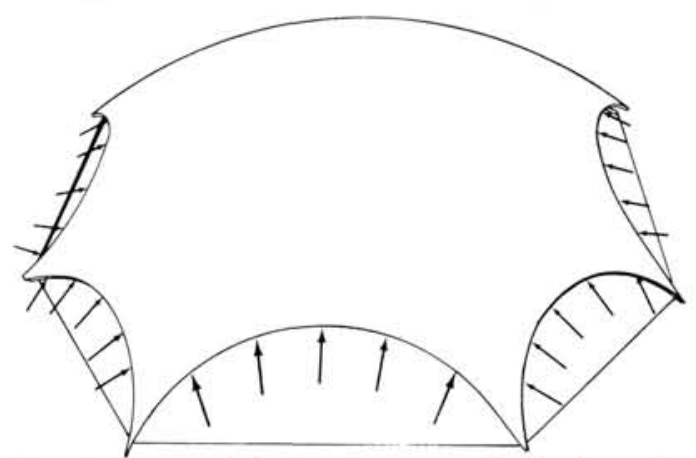

Fig. 29.-Tensiones principales de compresión ideales en los pun. tos de intersección con los lunetos.

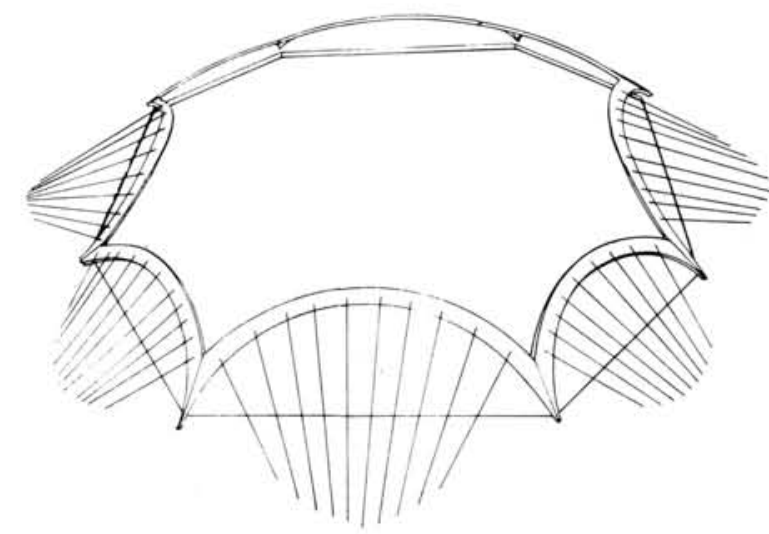

Fig. 30.-Materialización de las tensiones principales de borde mediante tirantes anclados en la terraza.

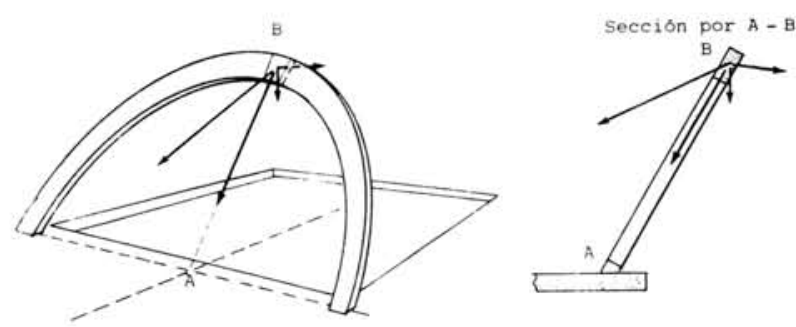

Fig. 31.-Tirantes interiores de compensación a fin de que la resultante de las cargas, se sitúe en el plano inclinado del arco. como las armaduras, necesarias ahora para absorber unos momentos que generan la microfisuración de la cúpula; todo porque, desaparecida la continuidad del apoyo, no actúan en los bordes de los lunetos las reacciones que antes se distribuian uniformemente en el paralelo del apoyo.

Retornando a la solución ideal del casquete esférico completo, podremos deducir, con toda facilidad, no sólo las reacciones en su anillo circular de apoyo, sino también las compresiones horizontales a que está sometido cada paralelo asi como las compresiones meridianas, tensiones ambas que sólo dependen de la latitud o distancia al polo. Cortemos ahora imaginariamente el casquete por los planos que contienen la vidriera de los lunetos. Si en cada uno de los puntos de intersección (un arco de circunferencia) suponemos aplicada, comó carga exterior (figura 29), una fuerza igual a la compresión que en ese punto existiria si no hubiera lunetos, resulta que el casquete esférico que ahora queda, trabaja en las mismas condiciones ideales de membrana que al principio, ya que, por hipótesis, quedan rigurosamente satisfechas las condiciones de contorno en sus bordes.

El objetivo de anular los momentos de lámina, está plenamente logrado. La única dificultad que resta, es la de materializar esas fuerzas exteriormente aplicadas a lo largo de los círculos menores de los lunetos. A estos efectos, se comienza por construir los arcos de contorno que bordean los círculos menores de intersección de la vidriera con el casquete esférico. Las dimensiones de la sección transversal de esos arcos, ya no es la necesaria para dotar al borde de una gran rigidez como lo exige el cálculo laminar. Ahora basta con la minima precisa para resistir la acción de unas cargas iguales y contrarias a las que queremos introducir en el borde libre del casquete superior. Construidos esos arcos de contorno, arcos que estarán contenidos en el plano inclinado del correspondiente luneto, se los mantiene en esa posición mediante unos cables exteriores que, a modo de vientos o cabos de arriostramiento, se anclan provisionalmente en el espesor de la terraza del edificio (figura 30). La inclinación de esos tirantes está geométricamente definida. Su dirección corresponde a la de las tensiones principales de la figura 29. También la magnitud del esfuerzo ejercido por cada tirante está determinada, razón por la cual será preciso regular, mediante los oportunos gatos, el pretensado lateral ejercido sobre los diferentes arcos hormigonados en esta primera fase.

Pero el desequilibrio es bien patente. Los arcos, exentos, inclinados el ángulo preciso por condiciones de superficie de iluminación a través de las vidrieras, no compensarán con su peso el tirón lateral de los cables provisionales. Para impedir el vuelco hacia afuera de los arcos, se disponen, radialmente, unos tirantes adicionales (figura 31), unos tirantes que, junto con el pehttp://informesdelaconstruccion.revistas.csic.es 
so de los arcos inclinados y del tirón exterior, deben dar lugar a una resultante, no vertical sino contenida en el plano del arco a fin de que estos elementos soporten cómodamente y sin alabeos, la carga combinada ejercida sobre su directriz circular. Si estos tirantes internos se dispusieran horizontales y de arco a arco, las variaciones térmicas generarian unos perturbadores esfuerzos secundarios. Inversamente, si de ellos se cuelga un contrapeso y se regula su inclinación y su carga, la acción ejercida por los tirantes interiores puede considerarse como constante y, por tanto, prácticamente independiente de las variaciones térmicas y de las deformaciones diferidas.

Sometidos los arcos que configuran el contorno de las vidrieras a este estado artificial de cargas, la línea de presiones coincide casi exactamente con la directriz. Cualquier defecto de construcción, improbable pero siempre posible, se acusa en este instante crítico del pretensado de los arcos.

Una vez efectuadas estas maniobras, dispuestos los tirantes y reglados sus esfuerzos en cinco tensados sucesivos, se hormigona la cúpula totalmente apoyada en una cimbra y separada de los arcos por una junta que finalmente se rellena. Cuando el hormigón ha endurecido, se procede a un gradual destensado de los tirantes provisionales exteriores. Cada alambre que se afloja es una fuerza exterior que se introduce sobre el casquete esférico a través de los arcos que actúan como unas elásticas ballestas en tensión. Cada fuerza perimetral desbloqueada, produce un parcial descimbrado de la cúpula. Al final, el casquete superior hormigonado en esa segunda fase, se encuentra bordeado por las fuerzas precisas para lograr el comportamiento ideal como membrana, esquemáticamente representado en la figura 29.

Ninguna hipótesis se precisa admitir sobre la magnitud de las flechas y giros, ya que la cúpula se hormigona sobre los bordes de unos arcos previamente deformados. A su vez, éstos últimos, al no tener coartados sus movimientos, se deformarán libremente, durante la primera fase, con arreglo a sus verdaderas características mecánicas sin que la presencia de posibles deformaciones no elásticas, suponga una objeción a la validez del procedimiento. Sólo importa que sean resistentes y, para ello, la propia secuencia constructiva encierra una implícita prueba de carga.

La cúpula recupera la plenitud de su forma expresiva. Todo es funcional en sus líneas. Hasta el pesado anillo que, como una lámpara monumental, corona el eje vertical del patio, atrae la atención recabando el prota. gonismo de su especifica función resistente.

Con la finalidad de destacar la áspera belleza del hormigón, no se realizó tratamiento alguno sobre los paramentos del anillo de contrapeso ni en el intradós de

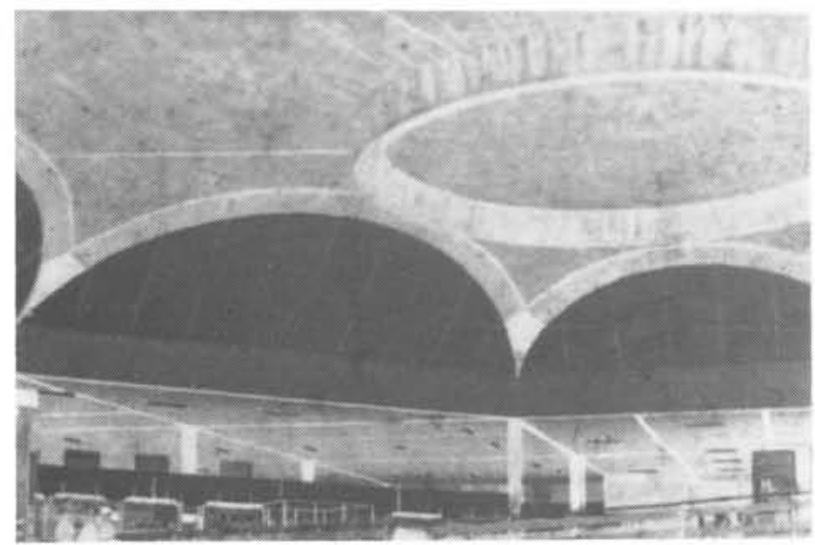

Fig. 32.-Vista interior de la cúpula, con su anillo de contrapeso como lámpara monumental.

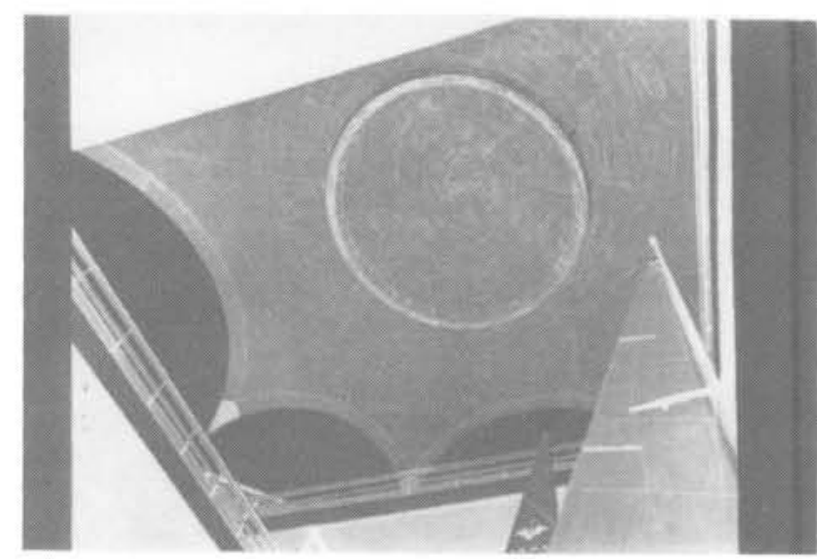

Fig. 33.-La cúpula, vista desde el interior del patio central.

la cúpula (figura 32). Los rehundidos del encofrado y las juntas de las maderas que sirvieron de molde, quedaron a la vista como sincera expresión de las propiedades de un material y de una estructura. El anillo de compensación, con sus $230 \mathrm{KN}$ de peso, parece flotar en el ambiente interior del patio con su quieto equilibrio (figura 33).

Una forma, para una función.

\section{SOLUCIONES MIXTAS}

Los problemas relativos a la evacuación del agua de lluvia, característico de las cúpulas invertidas, inducen a la búsqueda de soluciones basadas en superficies de doble curvatura. Un ejemplo típico de cubierta diseñada con arreglo a este criterio general, es la que se muestra en la figura 34. La compresión creada por los cables transversales, sobrecarga la acción de los tendones longitudinales o principales, más altos en el centro del recinto que en los bordes laterales, a fin de crear una divisoria o suave cumbrera dorsal a modo de cubierta a dos aguas. A poyada la lámina en la coronación del muro de recinto, ese contorno, generalmente ovalado o elíptico en planta, define una malla de nudos 


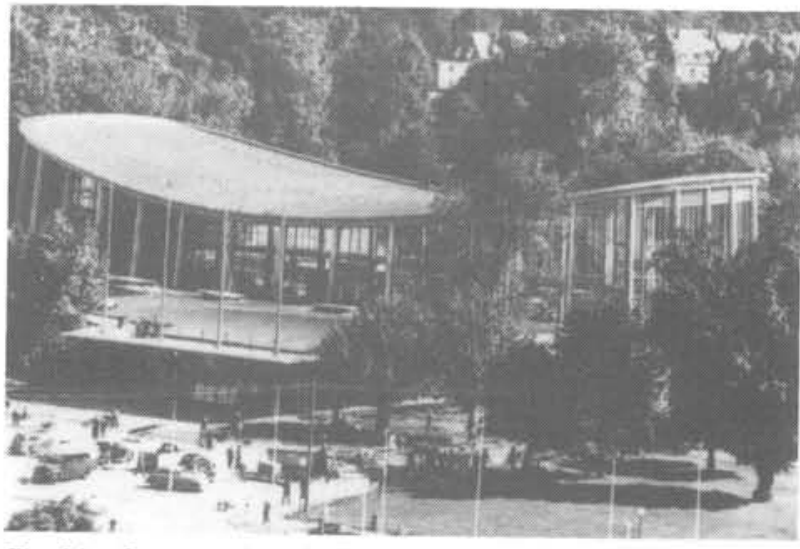

Fig. 34.-Centro emisor de Felsberg.

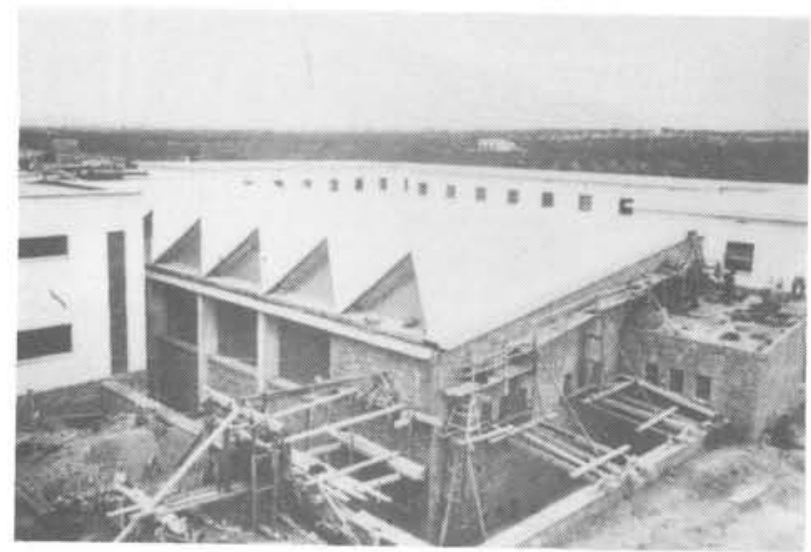

Fig. 35.-Aspecto de la cubierta de laboratorios de la Universidad Laboral de Tarragona.

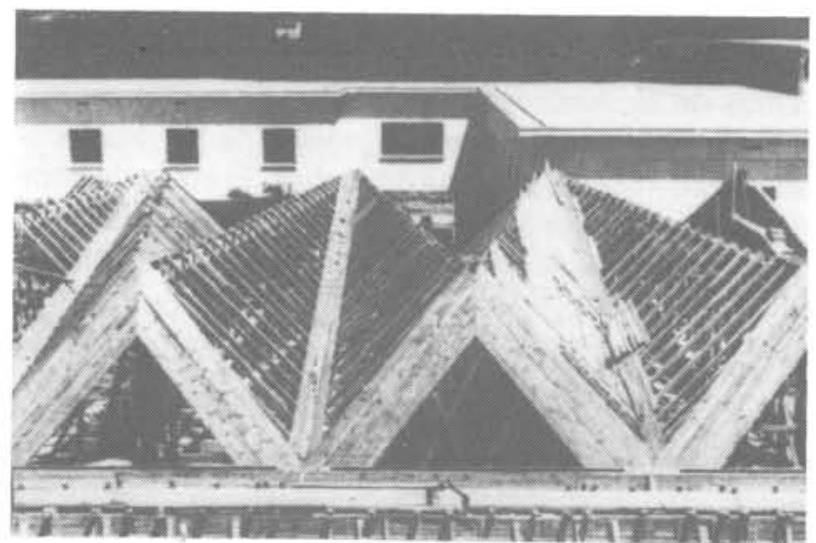

Fig. 36.-Disposición de las tablas del encofrado antes de colocar el forro.

ortogonales, formada por tendones de doble curvatura. Aun cuando, teóricamente, debería poderse formular una relación biunivoca entre el trazado genérico del borde de apoyo y la velaria definida por las catenarias de los trazados ideales de esa malla superficial de tendones ortogonales, no ha sido posible hasta el presente efectuar esa integración y dependencia, ni siquiera modulando el espesor de la lámina en cada punto para conseguir el deseable estado de bicompresiones constantes en toda la extensión de la cubierta. Las variantes basadas en un mínimo peso propio para alcanzar la máxima economía en las armaduras, tropieza con el grave inconveniente de la falta de estabilidad del conjunto bajo los efectos de un vendaval de mediana intensidad como consecuencia de las posibles succiones que puedan originarse.

Un planteamiento diametralmente opuesto es el origen del diseño de la estructura reproducida en la figura 35 , una cubierta que, curiosamente, se ha repetido en circunstancias bien diferentes para techar espacios dedicados a unas actividades dispares. La cumbrera de esa lámina plegada, está formada por un polígono de segmentos iguales, situados en un plano horizontal, que zigzaguea de una fachada a la opuesta, definiendo los lados superiores de una serie de triángulos iguales dispuestos con la misma pendiente y que se cortan entre si de un modo original. La mejor definición de esos planos lo constituye la sencilla disposición de los encofrados de esa lámina (figura 36). Interiormente las aristas de los diedros, así generados, quedan a la vista componiendo unos claroscuros que acentúan el contraste de la intersección (figura 37).

Funcionalmente estas láminas plegadas pueden considerarse, en una primera aproximación de diseño, co. mo un conjunto de vigas de sección rectangular, muy delgadas, cuyo plano de flexión se aparta de la vertical para formar un igual desplome de sus paramentos. El hecho de que esa variación del canto útil no sea la más apropiada a la correspondiente ley de momentos flectores, queda en parte compensado por la reciproca acción del faldón adyacente. La solución, más elemental, de sustituir esos triángulos por rectángulos o vigas con nervios igualmente inclinados respecto a la vertical pero de canto constante, parece una solución más lógica y sencilla, pero sin originalidad, un tanto caprichosa, de esa alternancia en la inclinación de las aristas de los sucesivos paneles.

Dentro de este grupo de soluciones mixtas, no puede faltar siquiera una referencia de la aplicación del pretensado a las cubiertas convencionalmente desarrolladas en la técnica del hormigón armado. Si descomponemos la techumbre en un elemento superficial o losa, y ęn unos nervios o dinteles de apoyo, llegaremos a la cobertura de un ambiente mediante la clásica disposición de unas vigas recubiertas, al par que solidarizadas, por un techo a modo de tablero. El acierto en la orientación de esos nervios de sustentación queda limitada a la expresión de su carácter resistente acorde con la función del recinto. Una distribución radial o en abanico de las jácenas, puede atraer la atención hacia un punto de convergencia, marcando así una singularidad en el ambiente interior. La figura 38 muestra el interior de un cine en donde los dinteles de unos semipórticos, parecen concentrarse sobre el escenario como 
punto principal donde confluye la atención de los espectadores.

La polémica suscitada en torno a la solución dada a la Basilica enterrada de Lourdes, no hace más que resaltar la personalidad del proyectista frente al planteamiento de un determinado problema. Huyendo de todo convencionalismo, las columnas de los pórticos dejan de presentar su fuste vertical para bifurcarse en dos elementos inclinados unidos en su base ligeramente despegada del suelo para alojar el estrangulamiento de unas rótulas plásticas (figura 39 ).

La solución puede impresionar a unos y disgustar tanto a otros como pará calificarla de suntuoso garaje. Forzoso es reconocer que la mitica figura de Freyssinet nos intimida de un modo decisivo a la hora de formular un juicio. Puesto que no se trata de emitir opiniones personales, nada mejor que transcribir el sentir del propio proyectista:

"Mi misión se ha limitado a indicar el principio de una solución muy simple y, sobre todo, defender su sencillez frente a toda tendencia hacia el inútil adorno. Ninguna consideración arquitectónica ha intervenido en la definición de las líneas interiores de la Basílica. Lourdes no hace más que continuar la vetusta tradición de las basilicas románicas y las primeras naves góticas, cuyas formas únicamente estuvieron determinadas por la técnica de la época en que se construyeron".

Sea cual fuere nuestra opinión particular sobre el modo de sentir el arte, lo que está fuera de toda duda es el hecho de que la Basilica de Lourdes es toda una muestra de las posibilidades del pretensado en el horizonte sin limites de la arquitectura. Si la función primaria de un recinto es la de albergar, es en la cubierta, como remate estructural, donde debemos centrar nuestra imaginación creadora.

\section{BIBLIOGRAFIA}

1. D. Viespescu, V. Petcu.

Essais de quelques voiles minces en béton précontraint.

IV Congr. FIP. Roma 1962.

\section{A. Páez}

La cúpula del recinto ferial.

Informes de la construcción n. ${ }^{\circ}$ 157. Febrero, 1964.

3. Eugène Freyssinet

Exposé d'ensemble de l'idée de la précontrainte. Travaux n.3 375 . París, Abril 1966.

\section{J. B. Ripoll}

Aplicaciones del pretensado en edificación Hormigón y acero n. 94. Julio, 1970.

(c) Consejo Superior de Investigaciones Científicas Licencia Creative Commons 3.0 España (by-nc)

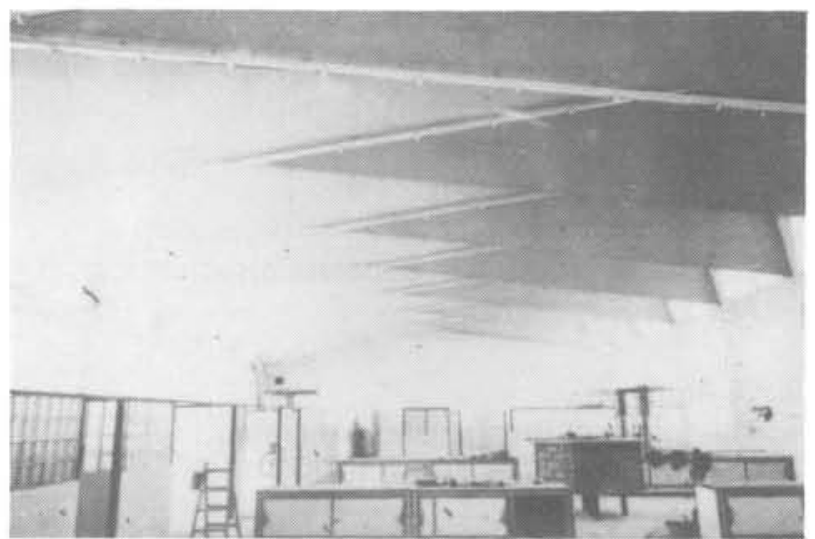

Fig. 37.-Interior de los laboratorios en donde se aprecia la incli. nación alternada de las intersecciones de los faldones.

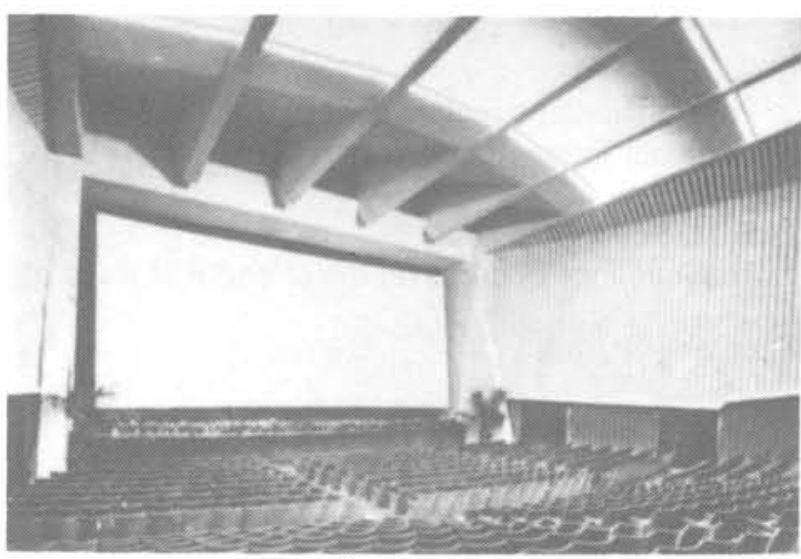

Fig. 38.-Cine Maestoso de Roma. Las vigas pretensadas del techo salvan un vano de 40 metros.

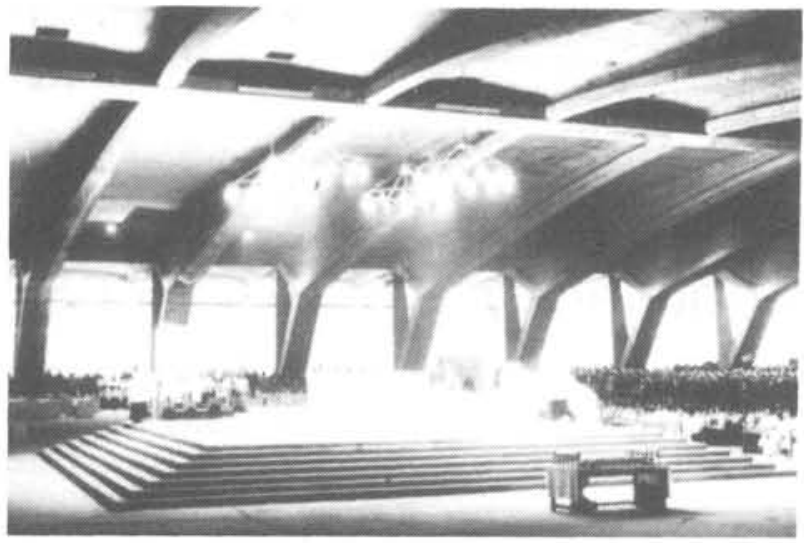

Fig. 39.-Basilica de Lourdes, proyectada por Freyssinet; un recinto enterrado de planta eliptica.

5. ACl Committee 344.

Design and construction of circular prestressed concrete structures.

ACl Journal. Septiembre, 1970.

6. G. G. Goble.

Optimum design of prestressed beams.

ACl Journal. Septiembre, 1971. 


\section{I. Martín}

Fullscale load test of a prestressed folded plate unit.

ACI Journal. Diciembre, 1971.

8. $\mathrm{ACl}$ Committee 224.

Control of cracking in concrete structures.

ACI 224 R-72. 1972.

9. O. Arup.

The future of prestressed concrete.

Concrete. Londres. Mayo, 1978.

10. W. T. Carrol, F. W. Beaufait, R. H. Bryan.

Prestressed concrete trusses.

$\mathrm{ACl}$ Journal. Agosto, 1978.

11. G. A. Koss.

Post-tensioned structure houses Dolphin stadium. Concrete International. Marzo, 1981.

12. E. M. Rego, F. L. Lobo

The influence of ducts on the strength of webs of prestressed concrete beams.

FIP Notes 92. Junio, 1981.

13. V. Jaría, A. Samartín.

Recomendaciones de la Asociación Internacional de Estructuras Laminares.

Hormigón y acero n.0 140. Septiembre, 1981.

14. N.D. Nathan.

Rational analysis and design of prestressed concrete beams and wall panels.

$\mathrm{PCl}$ Journal. Vol. 30, n. 3. Junio, 1985.

15. K. Sowlat, B. G. Rabbat.

Testing of segmental concrete girders with external tendons.

PCl Journal. Vol. 32, n. 2. Marzo-abril, 1987.

16. M. Virlogeux.

External prestressing of concrete.

FIP Notes 1987/2.

\section{publicación del IETcc / CSIC}

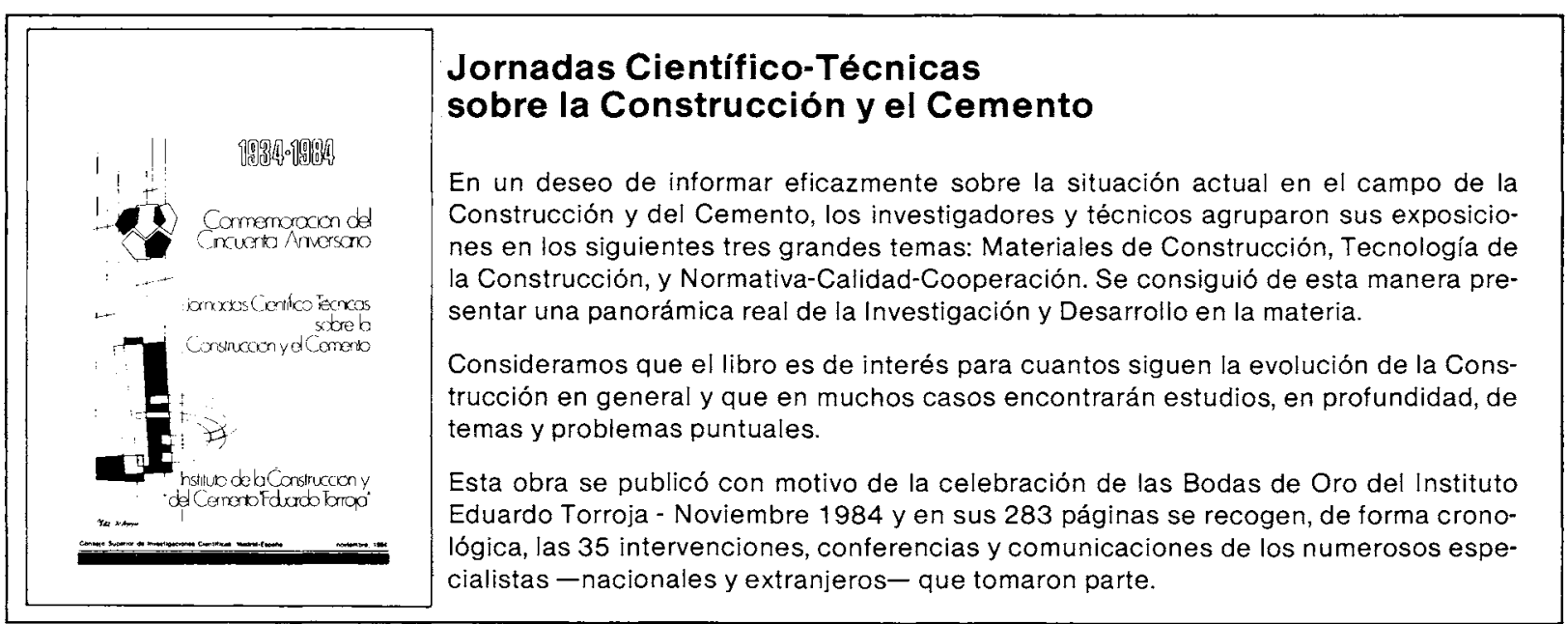

